\title{
Hambatan Bidan dalam Penggunaan Aplikasi SI CANTIK
}

\section{The Midwife Obstacles in The Usage Of SI CANTIK Application}

\author{
Eka Fitria Sari ${ }^{1}{ }^{1}$ Ernawaty ${ }^{1}$
}

\begin{abstract}
ABSTRAK
Latar Belakang: Salah satu upaya Dinas Kesehatan Kabupaten untuk menurunkan angka kematian ibu pada tahun 2018 adalah evaluasi dan optimalisasi Penakib melalui aplikasi SI CANTIK Namun sampai Desember 2019 jumlah bidan yang selalu menggunakan aplikasi SI CANTIK hanya sebanyak 62 orang (15,7\%) dari 394 orang. Tujuan: Tujuan penelitian ini adalah untuk menganalisis hambatan bidan dalam menggunakan aplikasi SI CANTIK di wilayah kerja 8 puskesmas Kabupaten Sidoarjo.

Metode: Penelitian berjenis observasional dengan rancang bangun cross sectional dan pendekatan deskriptif kuantitatif. Sampel penelitian adalah 32 bidan yang diambil melalui teknik purposive sampling. Data dianalisis dengan analisis statistik deskriptif menggunakan uji chi square.

Hasil: Hasil penelitian menunjukkan bahwa hanya terdapat 16 responden $(50,0 \%)$ yang selalu menggunakan aplikasi SI CANTIK. 19 responden $(59,3 \%)$ merasa hambatan terbesar dalam penggunaan aplikasi SI CANTIK disebabkan oleh aplikasi. 6 responden $(18,8 \%)$ diantaranya berpendapat penggunaan aplikasi SI CANTIK menghabiskan waktu lama. Sedangkan hasil uji chi square dalam tabulasi silang dapat disimpulkan bahwa terdapat hubungan yang signifikan antara variabel frekuensi penggunaan aplikasi SI CANTIK dan variabel hambatan penggunaan aplikasi SI CANTIK.

Kesimpulan: Terdapat hubungan yang signifikan antara variabel frekuensi penggunaan aplikasi SI CANTIK dan variabel hambatan penggunaan aplikasi SI CANTIK. Namun belum semua bidan selalu menggunakan aplikasi SI CANTIK dan hambatan terbesarnya adalah hambatan yang disebabkan oleh aplikasi. Dinas Kesehatan perlu menkaji ulang aplikasi SI CANTIK dan mengadakan pelatihan. Puskesmas perlu menindaklanjuti pelatihan serta memastikan bidan mendapatkan jaringan internet yang memadai.
\end{abstract}

Kata kunci: hambatan, penggunaan aplikasi si cantik

\begin{abstract}
Background: One of Sidoarjo District Health Office efforts to reduce maternal mortality in 2018 was Penakib evaluation and optimization through the SI CANTIK application. But until December 2019 the number of midwives who always used SI CANTIK application was only 62 people (15.7\%) out of 394 people.

Objectives: The purpose of this study was to analyze the midwife obstacles in the usage the SI CANTIK application in the work area of 8 Sidoarjo health centers.

Methods: The research type was observational with cross sectional design and quantitative descriptive approach. The sample study was 32 midwives taken through purposive sampling technique. Data were analyzed using descriptive statistical analysis which is the chi square test.

Results: The results showed that there were 16 respondents (50.0\%) who always used SI CANTIK application. 19 respondents $(59.3 \%)$ felt the biggest obstacle in the usage of SI CANTIK application was caused by the application. 6 respondents (18.8\%) among them thought the usage of SI CANTIK application took a long time. While the results of the chi square test in cross tabulation concluded that there is a significant relation between frequency and obstacles in usage of the SI CANTIK application.

Conclusions: There is a significant relation between frequency and obstacles in usage of the SI CANTIK application. However, not all midwives always use the SI CANTIK application and the biggest obstacle is the obstacle caused by the application. The Health Office needs to review the SI CANTIK application and conduct training. Puskesmas need to follow up training and ensure midwives get adequate internet networks.
\end{abstract}




\author{
*Koresponden: \\ eka.fitria.sari-2016@fkm.unair.ac.id \\ Eka Fitria Sari \\ ${ }^{1}$ Departemen Administrasi dan Kebijakan Kesehatan, Fakultas Kesehatan Masyarakat, Universitas Airlangga, \\ Kampus C Mulyorejo, 60115, Surabaya, Jawa Timur, Indonesia
}

\title{
PENDAHULUAN
}

Meninjau pencapaian Angka Kematian Ibu (AKI) di Jawa Timur tahun 2015-2018, jumlah kematian ibu dan angka kematian ibu di Kabupaten Sidoarjo relatif fluktuatif. Pada 2017 terjadi peningkatan dengan 30 ibu yang meninggal, sedangkan pada 2018 terjadi penurunan dengan $23 \mathrm{ibu}$ yang meninggal. Berdasarkan profil kesehatan Jawa Timur, kedua angka tersebut menjadikan Sidoarjo termasuk dalam 10 wilayah dengan jumlah kematian ibu terbanyak di Jawa Timur dengan posisi ketiga pada tahun 2017 dan keenam pada tahun 2018. Hal ini bukan merupakan pencapaian, melainkan masalah yang harus diatasi. terpecahkan.

Dinas Kesehatan Kabupaten Sidoarjo dalam profil kesehatannya menyatakan bahwa salah satu upaya penurunan AKI tahun 2018 adalah dengan mengevaluasi dan mengoptimalkan Penurunan Angka Kematian Ibu dan Angka Kematian Bayi (Penakib) melalui software aplikasi SI CANTIK (Sidoarjo Mencegah Kematian Ibu dan Anak). Aplikasi yang telah disusun sejak 2017 dan secara resmi diterapkan pada 21 April 2018 tersebut ditujukan untuk semua petugas kesehatan yang menyediakan pelayanan kepada ibu hamil (Dinas Kesehatan Kabupaten Sidoarjo, 2017). Tujuan penyusunannya adalah untuk memudahkan proses pencatatan, penyimpanan, pencarian dan pelaporan data ibu hamil di Sidoarjo sehingga dapat mencegah terjadinya kematian Ibu dan Anak. Salah satu keuntungan penggunaannya adalah apabila terdapat ibu hamil dengan resiko tinggi maka dapat segera diidentifikasi dan diberikan intervensi untuk mencegah terjadinya komplikasi sehingga keselamatan ibu menjadi prioritas utama (Dinas Kesehatan Kabupaten Sidoarjo, 2018). Di penghujung tahun 2018, aplikasi ini juga telah disosialisasikan ke seluruh fasilitas pelayanan kesehatan baik rumah sakit, puskesmas mandiri, maupun puskesmas yang memiliki pelayanan bagi ibu hamil.

Namun fakta yang tertuang pada data rasio kunjungan ibu hamil dalam aplikasi SI CANTIK sesuai tabel 1.3 menunjukkan bahwa sampai Desember 2019, jumlah bidan yang menggunakan aplikasi SI CANTIK hanya sebanyak 62 orang $(15,7 \%)$ dari total jumlah bidan di Kabupaten Sidoarjo yang berjumlah 394 orang. Dapat disimpulkan bahwa pengguna aplikasi SI CANTIK ini masih rendah. Seharusnya setiap bidan yang secara administratif bekerja di wilayah kerja puskesmas pasti akan memiliki pasien ibu hamil karena adanya jadwal piket pemberian pelayanan di puskesmas pada setiap bulannya termasuk untuk bidan desa.

Sehingga tujuan penelitian adalah menganalisis hambatan bidan dalam menggunakan aplikasi SI CANTIK di wilayah kerja puskesmas Kabupaten Sidoarjo. Manfaat penelitian adalah sebagai bahan evaluasi bagi Dinas Kesehatan Kabupaten Sidoarjo untuk meningkatkan penggunaan aplikasi SI CANTIK dan penggunaannya menjadi tepat tujuan, sebagai bahan masukan bagi puskesmas dalam terciptanya ketertiban tenaga kesehatan menggunakan aplikasi SI CANTIK, dan sebagai penerapan ilmu pengetahuan yang diperoleh oleh peneliti selama perkuliahan serta menambah wawasan dan pengalaman secara langsung mengenai upaya peningkatan penggunaan aplikasi SI CANTIK.

\section{METODE}

Penelitian ini merupakan penelitian yang berjenis observasional dengan rancang bangun cross sectional karena tidak ada intervensi dari peneliti dan pengambilan datanya dilakukan secara serentak pada satu waktu. Penyampaian hasil dilakukan dengan pendekatan deskriptif kuantitatif dengan penyimpulan melalui data angka berdasarkan 2 variabel yang diteliti yakni frekuensi penggunaan aplikasi SI CANTIK dan hambatan penggunaan aplikasi SI CANTIK. Populasi dalam penelitian ini adalah bidan puskesmas dan bidan desa yang secara administratif masih bekerja di wilayah kerja puskesmas Kabupaten Sidoarjo pada tahun 2019 yang berjumlah 394 bidan. Sedangkan sampel penelitian merupakan 32 bidan yang tersebar dalam 8 Puskesmas lokasi penelitian antara lain Puskesmas Candi, Puskesmas Ganting, Puskesmas Kedungsolo, Puskesmas Krian, Puskesmas Medaeng, Puskesmas Tanggulangin, Puskesmas Urangagung, dan Puskesmas Waru. Perhitungan besar sampel menggunakan teknik purposive sampling berdasarkan kriteria 4 Bidan yang Puskesmasnya masih memiliki kejadian kematian Ibu sampai September 2019 dan penelitian dilaksanakan mulai Oktober 2019 sampai Desember 2019. Sedangkan analisis data dilakukan dengan analisis statistik deskriptif menggunakan uji chi square. Data disajikan dalam bentuk distribusi frekuensi setiap variabel tabulasi silang kedua variabel.

\section{HASIL DAN PEMBAHASAN}

\section{Frekuensi Penggunaan Aplikasi SI CANTIK}

Analisis frekuensi penggunaan aplikasi SI CANTIK berfungsi untuk mengetahui kekerapan penggunaan aplikasi SI CANTIK yang dijalani oleh responden sebagai bidan. Terdapat 3 pilihan jawaban dari pertanyaan 
mengenai frekuensi penggunaan aplikasi SI CANTIK ini, antara lain: jarang, kadang-kadang, dan selalu. Distribusi frekuensi variabel frekuensi penggunaan aplikasi SI CANTIK ditampilkan dalam tabel 1.

Tabel 1. Distribusi Frekuensi Variabel Frekuensi Penggunaan Aplikasi SI CANTIK di Wilayah Kerja 8 Puskesmas Kabupaten Sidoarjo Tahun 2019

\begin{tabular}{|c|c|c|}
\hline Frekuensi Penggunaan Aplikasi SI CANTIK & $\mathbf{n}$ & $\%$ \\
\hline Jarang & 3 & 9,4 \\
\hline Kadang-kadang & 13 & 40,6 \\
\hline Selalu & 16 & 50,0 \\
\hline Total & 32 & 100,0 \\
\hline
\end{tabular}

Tabel 1 menunjukkan bahwa terdapat 3 responden $(9,4 \%)$ yang masih jarang menggunakan aplikasi SI CANTIK. Sedangkan untuk responden yang penggunaannya kadang-kadang sebanyak 13 responden $(40,6 \%)$. Serta jumlah responden yang selalu menggunakan aplikasi SI CANTIK sebanyak 16 responden (50,0\%). Hal ini dapat diartikan bahwa perbandingan antara bidan yang selalu menggunakan aplikasi SI CANTIK dengan bidan yang belum selalu (jarang dan kadang-kadang) menggunakan aplikasi SI CANTIK adalah 1:1. Hanya setengah $(50,0 \%)$ dari total responden yang sudah rutin atau selalu menggunakan aplikasi SI CANTIK.

Persepsi kemudahan penggunaan aplikasi SI CANTIK mempengaruhi penggunaan aplikasi SI CANTIK secara langsung (Ludyaningrum, 2018). Seorang bidan akan selalu menggunakan aplikasi SI CANTIK ketika ia merasa aplikasi SI CANTIK mudah digunakan. Kemudahan penggunaan aplikasi SI CANTIK dapat dilihat berdasarkan hambatan yang didapatkan bidan selama menggunakan aplikasi SI CANTIK. Semakin sedikit hambatan yang didapatkan bidan maka semakin mudah aplikasi SI CANTIK digunakan. Semakin mudah aplikasi SI CANTIK digunakan maka akan semakin sering bidan menggunakannya.

Penelitian Ludyaningrum (2018) menyatakan bahwa untuk menggunakan aplikasi SI CANTIK diperlukan niat. Niat untuk menggunakan aplikasi SI CANTIK dibuktikan dipengaruhi oleh beberapa faktor, salah satunya adalah persepsi kemudahan penggunaan. Hasil penelitian menunjukkan bahwa responden masih mengalami kesulitan dalam menerapkan atau mengoperasikan sistem informasi SI CANTIK. Kesulitan tersebut meliputi beratnya upaya mempelajari sistem, mengingat prosedur umum menggunakan sistem, mengingat cara pengisian data, dan kemudahan operasi sistem yang dirasakan oleh responden.Hasil penelitian Pramiyati dkk (2019) yang berkaitan dengan penerimaan pengguna SIMBUMIL juga menunjukkan bahwa bidan mengaku merasa mudah untuk menggunakannya karena pengisian yang disajikan sesuai dengan hasil pemeriksaan yang dilakukan. Oleh karena itu banyak bidan yang dapat menerima keberadaan SIMBUMIL tersebut dan sering menggunakannya.

\section{Hambatan Pengguna Aplikasi SI CANTIK}

Analisis hambatan penggunaan aplikasi SI CANTIK berfungsi untuk mengetahui kesulitan yang didapatkan responden sebagai bidan ketika menggunakan aplikasi SI CANTIK. Terdapat 6 pilihan jawaban dari pertanyaan mengenai hambatan penggunaan aplikasi SI CANTIK ini, antara lain: tidak terhambat, terhambat bukan karena aplikasi, dan terhambat karena aplikasi. Distribusi frekuensi variabel hambatan penggunaan aplikasi SI CANTIK ditampilkan dalam tabel 2. Tabel 2 menunjukkan bahwa terdapat 4 responden (12,6\%) yang merasa tidak memiliki hambatan ketika menggunakan aplikasi SI CANTIK. Sedangkan untuk responden yang merasa terhambat tetapi tidak disebabkan oleh kelemahan aplikasi SI CANTIK sebanyak 9 responden $(28,1 \%)$. Namun jumlah responden yang merasa terhambat karena kelemahan aplikasi SI CANTIK ketika menggunakan sebanyak 19 responden $(59,3 \%)$. Hal ini dapat diartikan bahwa mayoritas responden merasa terhambat karena kelemahan aplikasi SI CANTIK.

Tabel 2. Distribusi Frekuensi Variabel Hambatan Penggunaan Aplikasi SI CANTIK di Wilayah Kerja 8 Puskesmas Kabupaten Sidoarjo Tahun 2019

\begin{tabular}{lcc}
\hline \multicolumn{1}{c}{ Hambatan Penggunaan Aplikasi SI CANTIK } & n & \% \\
\hline Tidak Terhambat & 4 & 12,6 \\
\hline Terhambat Bukan Karena Kelemahan Aplikasi & 9 & 28,1 \\
\hline Terhambat Karena Kelemahan Aplikasi & 19 & 59,3 \\
\hline \multicolumn{1}{c}{ Total } & 32 & 100,0 \\
\hline
\end{tabular}

Besarnya jumlah responden yang merasa terhambat karena kelemahan aplikasi SI CANTIK ketika menggunakannya sesuai dengan penelitian Sari dkk (2017) dan Purwo dkk (2013). Sari dkk (2017) dalam penelitiannya menyebutkan bahwa kelemahan aplikasi masih ditemukan dalam evaluasinya. Kelemahan tersebut antara lain lemahnya password, tidak diberlakukannya batasan waktu akses aplikasi diluar jam kerja, penundaan 
fasilitas menu help, masih mungkin terdapat data tidak benar, perbaikan masih dilakukan pada saat jam kerja, pembaharuan prosedur baru pada aplikasi masih belum diterima perubahannya oleh user, dan kemungkinan sulitnya meminta pertanggungjawaban apabila laporan disalahgunakan dapat terjadi dikarenakan belum ada pencatatan secara tertulis untuk setiap pihak yang meminta. Sedangkan peneltian Purwo dkk (2013) menyebutkan bahwa hambatan penggunaan aplikasi secara umum disebabkan oleh kelemahan aplikasi. Kelemahan tersebut berada pada integrasi antar fitur terkait dengan update data, pengendalian yang tidak merata dan konsisten, tidak ada penggolongan yang jelas, beberapa fitur yang tidak berfungsi dengan baik, dan kesalahan sistem dalam memproses angka.

Dalam penelitian ini, hambatan penggunaan aplikasi SI CANTIK yang bukan disebabkan oleh kelemahan aplikasi diklasifikasikan antara lain karena: buruknya koneksi internet, pasien tidak membawa kartu identitas, dan bidan lupa menginput data dalam aplikasi SI CANTIK. Sedangkan hambatan penggunaan aplikasi SI CANTIK yang disebabkan oleh kelemahan aplikasi diklasifikasikan antara lain karena: proses input data sulit, proses login sulit, pertanyaan terlalu banyak, data tidak terintegrasi, dan penggunaan yang menghabiskan waktu lama. Klasifikasi hambatan tersebut ditampilkan dalam tabel 3.

Tabel 3. Distribusi Frekuensi Klasifikasi Hambatan Penggunaan Aplikasi SI CANTIK di Wilayah Kerja 8 Puskesmas Kabupaten Sidoarjo Tahun 2019

\begin{tabular}{lrr}
\hline \multicolumn{1}{c}{ Klasifikasi Hambatan Penggunaan Aplikasi SI CANTIK } & $\mathbf{n}$ & $\boldsymbol{\%}$ \\
\hline Tidak Terhambat & 4 & 12,5 \\
\hline Buruknya Koneksi Internet & 4 & 12.5 \\
\hline Pasien Tidak Membawa Kartu Identitas & 3 & 9,4 \\
\hline Bidan Lupa Menginput Data & 2 & 6,3 \\
\hline Proses Input Data Sulit & 4 & 12,5 \\
\hline Proses Login Sulit & 4 & 12,5 \\
\hline Pertanyaan Terlalu Banyak & 3 & 9,4 \\
\hline Data Tidak Terintegrasi & 2 & 6,3 \\
\hline Penggunaan menghabiskan Waktu Lama & 6 & 18,8 \\
\hline & Total & 32 \\
\hline
\end{tabular}

Tabel 3 menunjukkan bahwa terdapat masing-masing 2 responden $(6,3 \%)$ yang menyetujui hambatan karena responden yang merasa seringkali lupa menginput data aplikasi SI CANTIK dan beranggapan bahwa data dalam aplikasi SI CANTIK tidak terintegrasi. Mempertimbangkan usia responden, memang sebagian besar termasuk dalam kelompok usia lansia (46-65 tahun) yakni sebanyak 18 orang (56,3\%). Penelitian Kushariyadi (2016) menyebutkan bahwa secara fisiologis lansia akan mengalami penurunan fungsi kognitif (daya ingat) yang bersifat ireversibel. Oleh karena itu kemungkinan bidan merasa terhambat karena seringkali lupa ketika menginput data dalam aplikasi SI CANTIK dapat dinilai wajar. Namun hambatan ini bukan termasuk dalam hambatan karena kelemahan aplikasi SI CANTIK, melainkan hambatan karena kelemahan faktor sumber daya manusia. Berbeda dengan anggapan bahwa data dalam aplikasi SI CANTIK tidak terintegrasi, anggapan tersebut merupakan hambatan karena kelemahan aplikasi SI CANTIK. Dalam penelitian Muslim (2018) disebutkan bahwa sistem informasi yang baik untuk diterapkan di instansi adalah sistem informasi yang terintegrasi. Penerapannya mampu memberi beberapa keuntungan yang berpengaruh pada PT seperti mencapai hasil yang akurat, efektif, dan efisien.

Dalam tabel 3 disebutkan juga bahwa terdapat masing-masing 3 responden $(9,4 \%)$ yang menyetujui hambatan karena pasien seringkali tidak membawa kartu identitas sehingga bidan tidak mengetahui NIK (Nomor Induk Kependudukan) pasien serta beranggapan pertanyaan yang harus diisi dalam aplikasi SI CANTIK terlalu banyak. Faktor sumber daya manusia tidak hanya berhubungan dengan bidannya saja tetapi juga dengan pasiennya. Hal ini dikarenakan penggunaan aplikasi SI CANTIK yang berhubungan dengan NIK pasien. Pasien dipaksa untuk kooperatif dengan menghafal NIKnya atau membawanya ketika melakukan pemeriksaan. Tetapi yang seringkali terjadi pasien tidak hafal dengan NIKnya karena terlalu panjang dan tidak membawa kartu identitas seperti KK (Kartu Keluarga) atau KTP (Kartu Tanda Penduduk) sehingga bidan tidak mengetahui NIK pasien. Pramiyati dkk (2019) menyebutkan dalam penelitiannya mengenai penerimaan aplikasi SIMBUMIL bahwa jendela pencarian menggunakan identitas nama pasien. Hal ini mungkin dapat menjadi sebuah inovasi untuk aplikasi SI CANTIK yang menambahkan nama menjadi data utama, selain NIK. Walaupun sebenarnya kualitas NIK sebagai primary key lebih baik dibandingkan nama yang memiliki kemungkinan sama labih besar. Bidan Untuk mengatasinya, bidan sebagai tenaga kesehatan yang memberi pelayanan dapat berinisiatif berusaha lebih keras lagi untuk mendapatkan NIK pasien. Misalkan dengan meminta nomor telepon pasien dan menghubunginya kembali ketika pasien sudah di rumah untuk mendapatkan NIKnya. Sehingga hambatan mengenai pasien yang tidak membawa KTP bukan termasuk dalam hambatan karena kelemahan aplikasi SI CANTIK, melainkan hambatan karena kelemahan faktor sumber daya manusia. Berbeda dengan anggapan bahwa pertanyaan yang harus diisi dalam 
aplikasi SI CANTIK terlalu banyak, anggapan tersebut merupakan hambatan karena kelemahan aplikasi SI CANTIK. Teknologi yang penggunaannya rumit dan memerlukan banyak waktu untuk dipelajari akan membuat pengguna merasa bahwa teknologi tersebut tidak memberikan kemudahan bagi pekerjaannya tetapi justru membebani dalam proses penggunaannya Purnamaningsih dkk (2018).

Tidak hanya itu, tabel 3 juga menyebutkan bahwa terdapat masing-masing 4 responden (12,5\%) yang merasa tidak terhambat. 4 responden $(12,5 \%)$ lainnya masing-masing tetapi merasa terhambat karena proses input data dan proses login yang sulit, dan buruknya koneksi internet. Kesulitan pada proses input data dan login yang dikeluhkan oleh responden termasuk dalam hambatan karena kelemahan aplikasi SI CANTIK. Hal ini biasa terjadi karena buruknya penggunaan dan pemilihan kosakata dalam aplikasi sehingga bidan sebagai pengguna sulit untuk memahami. Selain itu tidak ada instruksi lain yang memperjelas cara penggunaanya. Hal ini selaras dengan penelitian Pramiyati dkk (2019) yang menyebutkan bahwa kolom pencarian dalam aplikasi SIMBUMIL dituliskan dengan redaksi "search" atau kata pencarian namun dalam bahasa inggris. Sedangkan tidak semua bidan memiliki kemampuan bahasa inggris dan mengerti arti kata "search". Oleh karena itu Pramiyati dkk (2019) menyarakan kata "search" diubah redaksinya menjadi "pencarian" agar perintah aplikasi lebih mudah dipahami oleh bidan sebagai pengguna. Hal ini yang mungkin dapat diterapkan juga dalam aplikasi SI CANTIK. Redaksi kata yang masih menggunakan kata dalam bahasa inggris lebih baik diubah dalam Bahasa Indonesia agar aplikasi SI CANTIK lebih mudah digunakan. Selain itu terdapat hambatan lain yang bukan termasuk dalam hambatan karena kelemahan aplikasi SI CANTIK yakni buruknya koneksi internet. Peran jaringan internet dalam penggunaan aplikasi SI CANTIK cukup besar. Walaupun dapat diakses dengan smartphone, untuk mengakses aplikasi SI CANTIK dibutuhkan ketersediaan jaringan internet. Sehingga walaupun tersedia perangkat smartphone, aplikasi SI CANTIK tetap tidak dapat diakses jika jaringan internet tidak tersedia. Tetapi yang terjadi di lapangan, mayoritas bidan menyerah menggunakan aplikasi SI CANTIK ketika terhambat oleh jaringan internet, baik karena faktor signal di lokasi yang kurang memadai maupun ketidaksediaan bidan menyediakan jaringan internet yang memadai. Putri dan Jumhur (2019) menyatakan dalam penelitiannya bahwa untuk menggunakan suatu sistem memang diperlukan adanya infrastruktur dan teknis yang memadai seperti smartphone berbasis android, pulsa data, dan jaringan internet. Penggunaan sistem juga mengharuskan pengguna memiliki keterampilan khusus seperti mengoperasikan smartphone berbasis android dan menghubungkannya ke jaringan internet.

Sedangkan yang menjadi hambatan terbesar bidan dalam menggunakan aplikasi SI CANTIK adalah penggunaannya yang menghabiskan waktu lama. Terdapat 6 responden $(18,8 \%)$ yang merasakan hambatan tersebut dalam tabel 3. Hambatan ini merupakan bagian dari hambatan yang disebabkan oleh kelemahan aplikasi. Bidan memiliki anggapan bahwa menggunakan aplikasi SI CANTIK cukup rumit karena sulit memahami kondisi yang terjadi serta cukup memerlukan banyak waktu dari pekerjaan normal bidan. Waktu tersebut diperlukan baik untuk melakukan operasi mekanis (seperti input data) maupun mempelajari hasil penggunaan agar sepadan dengan usaha yang dikeluarkan. Beberapa bidan juga mengaku proses input data dalam aplikasi SI CANTIK sering kali terjadi secara berulang-ulang untuk data yang sama sehingga menghabiskan waktu. Tidak hanya itu, penggunaan aplikasi SI CANTIK yang belum maksimal membuat bidan tetap diharuskan mengisi sistem manual. Bidan tetap harus melakukan pencatatan dalam buku kohort dan buku register ibu hamil. Hal ini yang kemudian membuat bidan merasa memiliki beban kerja ganda. Beban kerja ganda tersebut yang kemudian menghabiskan waktu responden dalam memberikan pelayanan. Hal ini dapat terjadi karena terdapat beberapa hal dalam sistem manual yang tidak dapat dipenuhi dalam aplikasi SI CANTIK. Atau dapat dikatakan bahwa aplikasi SI CANTIK belum sesuai dengan persyaratan tugas yang harus diselesaikan pengguna. Widagdo and Susanto (2015) dalam penelitiannya menyatakan meskipun teknologi dapat dianggap sebagai sesuatu yang maju atau canggih, pengguna tidak akan mungkin menggunakan jika teknologi tidak sesuai dengan persyaratan tugas pengguna. Apabila teknologi tidak sesuai dengan persyaratan tugas pengguna, maka penggunaannya akan semakin memperberat pekerjaan pengguna. Kewajiban menggunakan teknologi akan semakin menambah beban kerja bidan sebagai pengguna.

\section{Tabulasi Silang Antara Variabel Frekuensi Penggunaan Aplikasi SI CANTIK dan Variabel Hambatan Penggunaan Aplikasi SI CANTIK}

Tabulasi silang digunakan untuk menginterpretasikan keterkaitan variabel frekuensi penggunaan aplikasi SI CANTIK dengan variabel hambatan penggunaan aplikasi SI CANTIK. Tabulasi silang antara variabel frekuensi penggunaan aplikasi SI CANTIK dan variabel hambatan penggunaan aplikasi SI CANTIK ditampilkan dalam tabel 4 . 
Tabel 4. Tabulasi Silang Antara Variabel Frekuensi Penggunaan Aplikasi SI CANTIK dan Variabel Hambatan Penggunaan Aplikasi SI CANTIK di Wilayah Kerja 8 Puskesmas Kabupaten Sidoarjo Tahun 2020

\begin{tabular}{|c|c|c|c|c|c|c|c|c|}
\hline \multirow[t]{2}{*}{$\begin{array}{l}\text { Hambatan Penggunaan } \\
\text { Frekuensi Penggunaan } \\
\text { Aplikasi SI CANTIK }\end{array}$} & \multicolumn{2}{|c|}{$\begin{array}{c}\text { Tidak } \\
\text { Terhambat }\end{array}$} & \multicolumn{2}{|c|}{$\begin{array}{l}\text { Terhamb } \\
\text { atBukan } \\
\text { Karena } \\
\text { Aplikasi }\end{array}$} & \multicolumn{2}{|c|}{$\begin{array}{c}\text { Terhambat } \\
\text { Karena } \\
\text { Aplikasi }\end{array}$} & \multicolumn{2}{|c|}{ Total } \\
\hline & $\mathbf{n}$ & $\%$ & $\mathbf{n}$ & $\%$ & $\mathbf{n}$ & $\%$ & $\mathbf{n}$ & $\%$ \\
\hline Jarang & 0 & 0,0 & 1 & 3,1 & 2 & 6,3 & 3 & 9,4 \\
\hline Kadang-kadang & 2 & 6,3 & 3 & 9,4 & 8 & 24,9 & 13 & 40,6 \\
\hline Selalu & 2 & 6,3 & 5 & 15,6 & 9 & 28,1 & 16 & 50,0 \\
\hline Total & 4 & 12,6 & 9 & 28,1 & 19 & 59,3 & 32 & 100,0 \\
\hline
\end{tabular}

Tabel 4 menunjukkan bahwa penyebab terbesar responden jarang menggunakan aplikasi SI CANTIK adalah karena terhambat oleh aplikasi yakni 2 dari 3 responden $(6,3 \%$ dari 9,4\%). Begitu pula dengan responden yang penggunaannya pada aplikasi SI CANTIK kadang-kadang, sebagian besar terhambat pula oleh aplikasi yakni 8 dari 13 responden (24,9\% dari 40,6\%). Tidak hanya itu, responden yang mengaku selalu menggunakan aplikasi SI CANTIK juga masih merasakan adanya hambatan dalam penggunaannya. Sebagian besar juga terhambat karena aplikasi, yakni 9 dari 16 responden $(28,1 \%$ dari 50,0\%). Hal ini menunjukkan bahwa memang hambatan terbesar yang didapatkan responden sebagai bidan ketika menggunakan aplikasi SI CANTIK adalah hambatan yang disebabkan oleh aplikasi yakni terdapat 19 responden $(59,3 \%)$. Hambatan tersebut antara lain proses input data sulit, proses login sulit, pertanyaan terlalu banyak, data tidak terintegrasi, dan penggunaan yang menghabiskan waktu lama.

Tabel 5. Hasil Uji Chi Square Antara Variabel Frekuensi Penggunaan Aplikasi SI CANTIK dan Variabel Hambatan Penggunaan Aplikasi SI CANTIK di Wilayah Kerja 8 Puskesmas Kabupaten Sidoarjo Tahun 2020

\begin{tabular}{rccr}
\hline & Value & df & Asymptotic Significance (2-sided) \\
\hline Pearson Chi-Square & 12,157 & 4 & 0,016 \\
\hline
\end{tabular}

Tabel 5 merupakan hasil uji Chi Square dalam tabulasi silang yang digunakan untuk menginterpretasikan keterkaitan variabel frekuensi penggunaan aplikasi SI CANTIK dengan variabel hambatan penggunaan aplikasi SI CANTIK. Dasar pengambilan keputusan adalah apabila nilai Asymp. Sig $>0,05$ maka tidak terdapat hubungan yang signifikan antara kedua variabel. Sedangkan apabila nilai Asymp. Sig $<0,05$ maka terdapat hubungan yang signifikan antara kedua variabel. Tabel 5 menunjukkan bahwa Asymp. Sig kedua variabel sebesar 0,016 (Asympt. Sig $<0,05)$. Sehingga dapat disimpulkan bahwa terdapat hubungan yang signifikan antara variabel frekuensi penggunaan aplikasi SI CANTIK dan variabel hambatan penggunaan aplikasi SI CANTIK.

\section{KESIMPULAN}

Hasil penelitian berdasarkan tabulasi silang menunjukkan bahwa frekuensi penggunaan masih 16 responden $(50,0 \%)$ yang sudah rutin atau selalu menggunakan aplikasi SI CANTIK. Hambatan terbesar yang didapatkan responden sebagai bidan ketika menggunakan aplikasi SI CANTIK adalah hambatan yang disebabkan oleh aplikasi yakni terdapat 19 responden (59,3\%). Dalam hambatan yang disebabkan oleh aplikasi, mayoritas responden memilih hambatan karena penggunaan aplikasi SI CANTIK yang menghabiskan waktu lama yakni 6 responden $(18,8 \%)$. Berdasarkan hasil uji chi square dalam tabulasi silang dapat disimpulkan bahwa terdapat hubungan yang signifikan antara variabel frekuensi penggunaan aplikasi SI CANTIK dan variabel hambatan penggunaan aplikasi SI CANTIK karena Asympt Sig. sebesar 0,016 atau Asympt Sig. < 0,05.

Saran yang dapat diberikan kepada Dinas Kesehatan Kabupaten Sidoarjo adalah hendaknya menkaji ulang sistem input aplikasi SI CANTIK baik dengan menambahkan nama ibu hamil untuk mencari data ibu hamil selain NIK, mengintegrasikan data, mengubah redaksi kata yang digunakan untuk memudahkan pengguna, dan melakukan sinkronisasi aplikasi SI CANTIK engan sistem manual. Tidak hanya itu, sebaiknya Dinas Kesehatan juga mengadakan pelatihan penggunaan aplikasi SI CANTIK walaupun hanya untuk beberapa perwakilan puskesmas saja. Sedangkan saran untuk pihak puskesmas hendaknya mengadakan pelatihan internal yang berkesinambungan dengan pelatihan yang diadakan oleh Dinas Kesehatan mengenai penggunaan aplikasi SI CANTIK serta ditambahakn dengan pelatihan manajemen waktu. Puskesmas juga perlu memastikan bidan mendapatkan jaringan internet yang memadai sebagai bentuk dukungan agar bidan rutin menggunakan aplikasi SI CANTIK.

\section{ACKNOWLEDGEMENT}

Ucapan terima kasih ditujukan kepada Dinas Kesehatan Kabupaten Sidoarjo yang telah mengizinkan penelitian ini dilakukan di 8 Puskesmas yang berada di wilayah Kabupaten Sidoarjo. 


\section{REFERENSI}

Dinas Kesehatan Kabupaten Sidoarjo (2017) Profil Kesehatan Kabupaten Sidoarjo Tahun 2017. Sidoarjo: Dinas Kesehatan Kabupaten Sidoarjo.

Dinas Kesehatan Kabupaten Sidoarjo (2018) Profil Kesehatan Kabupaten Sidoarjo Tahun 2018. Sidaorjo: DinasKesehatan Kabupaten Sidoarjo.

Kushariyadi (2016) 'Perawatan Daya Ingat Lansia Menggunakan Slow-Stroke Back Massage di Unit PelaksanaTeknis Panti Sosial Lanjut Usia Kabupaten Jember’, NurseLine Journal, 1(1), pp. 100-112.

Ludyaningrum, R. M. (2018) Analisis Penerimaan Pengguna Sistem Informasi Sidoarjo Cegah Angka KematianIbu dan Anak (SI CANTIK) Di Kabupaten Sidoarjo, Universitas Airlangga. Universitas Airlangga. doi: 10.1017/CBO9781107415324.004.

Muslim, B. (2018) 'Analisis SItem Informasi (SI) Terintegrasi DI Perguruan Tinggi (PT)', JUTIM, 10(2), pp.83-91.

Pramiyati, T., Jayanta and Mahfud, H. (2019) 'Analisis Tingkat Penerimaan Pengguna Terhadap SIMBUMIL (Hasil Survei Penerimaan SIMBUMIL di Puskesmas Mandalawangi)', Jurnal Ilmu Komputer dan Informatika,5(1), pp. 61-67.

Purnamaningsih, Erhan, T. P. and Rizkalla, N. (2018) 'Faktor-Faktor yang Mempengaruhi Penggunaan Application-Based Short Distance Delivery Service Telaah Pada Onlineshop Di Area Jabodetabek', ULTIMAmanagement, 10(2), pp. 110-119.

Purwo, N. W., Sugiarti, Y. and Sutanto, A. C. (2013) 'Evaluasi Application Control Pada Sistem Pembelian CV.X', Jurnal Ilmiah Mahasiswa Universitas Surabaya, 2(1), pp. 1-13.

Putri, R. A. and Jumhur, H. M. (2019) 'Peminat Aplikasi Blibli.com dengan Menggunakan Model Unified Theory of Acceptance and Use of Technology (UTAUT)', Jurnal Riset Bisnis dan Manajemen, 12(1), pp. 16-23.Sari, W. D. et al. (2017) 'Evaluasi Pengendalian Aplikasi pada Sistem Informasi Keuangan dan Akuntansi Satya Wacana (SIKASA)’, Jurnal Sistem Informasi Indonesia, 2(1), pp. 1-13.

Widagdo, P. P. and Susanto, T. D. (2015) 'Pengaruh Kesesuaian Teknologi Pada Tugas (Task Technology Fit) Terhadap Kinerja Individu dalam Menggunakan Teknologi Informasi (Studi Kasus: Universitas Mulawarman)',Prosiding Seminar Nasional Manajemen Teknologi XXIII, C(14), pp. 1-12. 